\title{
Role of Pharmacist in the epidemic, pandemic, and emergency public health with an emphasis on Coronavirus Disease (COVID-19)
}

\begin{abstract}
Yousef Ahmed Alomi* iD, BSc. Pharm, MSc. Clin Pharm, BCPS, BCNSP, DiBA, CDE, Critical Care Clinical Pharmacists, TPN Clinical Pharmacist, Freelancer Business Planner, Content Editor and Data Analyst, Riyadh, Saudi Arabia. Sultan Mohammed Al-Jarallah, Head, Ambulatory Care Pharmacy, Oncology and Hematology Clinical Pharmacist, Pharmaceutical Care Department, Security Forces Hospital, Riyadh, Saudi Arabia.
\end{abstract}

\section{Correspondence:}

Dr. Yousef Ahmed Alomi, BSc. Pharm, MSc. Clin Pharm, BCPS, BCNSP, DiBA, CDE, Critical care clinical pharmacists, TPN clinical pharmacist, Freelancer Business Planner, Content Editor and Data Analyst. P.O.BOX 100, Riyadh 11392, Riyadh, Saudi Arabia

Phone no: +966504417712

E-mail:yalomi@gmail.com
Received: 09-10-2020;

Accepted: 13-12-2020

Copyright: () the author(s), publisher and licensee International Journal of Pharmacology and Clinical Sciences. This is an open-access article distributed under the terms of the Creative Commons Attribution Non-Commercial License, which permits unrestricted non-commercial use, distribution, and reproduction in any medium, provided the original work is properly cited.

This is an open access article distributed under the terms of the Creative Commons Attribution-NonCommercial-ShareAlike 4.0 License

Access this article online

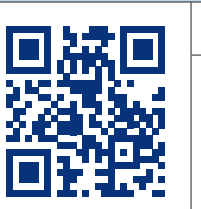

www.ijpcs.net

DOI:

10.5530/ijpcs.2021.10.1

\begin{abstract}
Objectives:To explore the role of Pharmacist in an epidemic, pandemic, and emergency public health with an emphasis on Coronavirus Disease (COVID-19). Methods: It is a new initiative services drove by national and international infection control, epidemic, pandemic, and medicine disaster guidelines. The projects formulated the latest project from pharmacy project guidelines, the international business model, and project management institution guidelines. Project management professionals steps write the initiative project. It consisted of several parts, including the initial phase, the planning phase, the execution phase, and the monitoring and controlling phase. Results: The Role of Pharmacists in the epidemic, pandemic, and emergency public health emphasizes COVID-19 with a defined vision, mission, and aims. The services had multiple benefits, including clinical and economical on patients, as illustrated in the review. The continuity of the project is assured by the risk management model description. Besides, the monitoring and controlling of the services as declared. The transition to operation project through the closing project stage is explored in the analysis. Conclusion: The Role of Pharmacists in the epidemic, pandemic, and emergency public health emphasizing COVID-19 is essential and beneficial. The Pharmacist might contribute to the infection control at the pharmacy and healthcare system, provide enough supply from medications, and be involved in public health education about epidemic or pandemic management; it is highly suggested to implement other counties in Saudi Arabia the world.

Key words: Pharmacist, Epidemic, Pandemic, Emergency, Public health, Disaster, Saudi Arabia.
\end{abstract}

\section{INTRODUCTION}

The pharmaceutical care concept was implemented in Saudi Arabia for more than 20 years by changing pharmacy practice. It implemented a Pharm d degree in the college of pharmacies. ${ }^{[1-3]}$ The general administration of pharmaceutical care established the first pharmacy strategic plan in the 2000s, and the first update had been done in 2012 and the second updated according to the Saudi vision 2030 in 2016. ${ }^{[4,5]}$ Over the past years, the Pharmacist showed significant improvement in the hospital pharmacy services in the governmental and private sectors. ${ }^{[6-8]}$ Besides, the Pharmacist showed a significant clinical outcome for patients care, prevent drug-related problems, and avoid unnecessary additional million US dollars annually. ${ }^{[9-17]}$ Besides, the Pharmacist plays vital roles during mass gatherings hajj period annually. ${ }^{[18]}$ All previous pharmacist performances were during the normal situation. However, during a disaster, problems with an emphasis on disaster medical or emergency public health will play a significant role. ${ }^{[19-25]}$ The national and international pharmacy societies and organizations released the role spectrum of Pharmacists with powerful performances in practice during the pandemic and emergency, public health on Coronavirus Disease (COVID-
19) had a. ${ }^{[26-32]}$ Besides; The Pharmacist accurately provides the services pre-disaster, during, and after disaster pandemic. Various studies showed the role of pharmacists during the pandemic and emergency public health. It was a unique Role of providing medications, sanitizers, drug-related problems during the pandemic situation, active surveillances of pharmacy infection control, patient management, provide immunization program to all public people. ${ }^{[33-40]}$ The authors are not familiar with any scientific evidence about pharmacists' role in the pandemic or emergency public health declared locally or Gulf and Middle East countries. The review project aims to explore the role of pharmacists during the pandemic and emergency public health, emphasizing coronavirus COVID-19 in the kingdom of Saudi Arabia.

\section{The Project's Method}

It is a new initiative project from international medical disaster and emergency public health programs. The task force team of pharmacists in pandemic and emergency public health formulated and consisted of the author's expertise in pharmacy practice, pharmacy administration, and clinical pharmacy. All other disaster medicine will be excluded from the revision. The committee 
reviewed the pharmacy administration guidelines, international litterateur pandemic, and emergency public health. Besides, and recent updates about coronavirus's national and international guidelines (COVID-19). It was written by utilizing the pharmacy project guidelines, the international business model, and project management institution guidelines of a new project. ${ }^{[41-44]}$ The Role of pharmacists in pandemic and emergency public health emphasizes COVID-19 adjusted based on pharmacists' role at the hospital pharmacy, community pharmacies, and ambulatory care services. The project is written by project management professionals and consisted of several sections, including the initial phase, the planning phase, the execution phase, and the monitoring and controlling phase.

\section{Initiative phase}

\section{Assessment needs}

During regular days, pharmacy staff's role, including the clinical Pharmacist or distributive pharmacist and pharmacy technician through procurement, preparation, and dispensing medications with drug monitoring, is pronounced. However, during the disaster situation, various changes are starting from providing medications from the stock supply, the incremental preparation and dispensing medications, and the management of various emergency services. Moreover, during disaster medicine with an emphasis on pandemic or emergency public health, multiple changes were implemented by following the local country emergency guidelines and world health organizations' regulations. As a result, the Role of the clinical Pharmacist or regular pharmacist and pharmacy technicians during a pandemic or emergency public health with an emphasis on COVID-19 needs to be implemented. Role of Pharmacist in pandemic and emergency public health with a focus on COVID-19required to prevent or stop the continuation of the pandemic virus, management of infected patients with appropriate antiviral, or vaccine and support therapy of antibiotics and related requirements medications at home or ambulatory care services, inpatient services and critical care units and community healthcare services.

Moreover, we need to declare a pharmacist's Role in preventing drug-related errors with new drug therapy of viruses creates a medication safety culture. The Pharmacist needs to meet healthcare professionals' workload over dispensing over the counter medications, sanitizer, and appropriate mask. Moreover, clinical pharmacists might play an active role during the therapeutic management of ambulatory care or acute and critically ill patients. Setup the management of new viral therapy and contribute during the clinical trial of new medications management for new COVID-19.

\section{SWOT analysis}

The SWOT analysis is considered one of the popular methods for each new project analysis. The SWOT analysis is declaring strength, weakness, opportunities, and threats. The project's strengths points are implemented Role of Pharmacist in pandemic and emergency public health with an emphasis on COVID19, provide enough supply from all required medications and accessories, setup up the medication safety, and prevent mistakes a pandemic and emergency public health. In contrast, the weak points are the high demand for medications and related accessories during emergency public health and pandemic situations. The healthcare system's busy with patients from the previous healthcare system. The opportunities points are high required of healthcare professionals, including pharmacists and pharmacy technicians, quality and setup of the patient safety program. If the pharmacy strategic plan does not exist, the threat points are if the administration planner is not available.

\section{Market Analysis}

The Role of the Pharmacist is well established in the kingdom of Saudi Arabia. The Pharmacist provides the services through the pharmaceutical care concept from procurement through preparation and dispensing medications and monitoring drug therapy. The clinical Pharmacist's Role declared thorough documentation of the clinical outcomes and economic impact on patients and the healthcare system at healthcare organizations. Most governmental or private healthcare organizations had clinical pharmacists, distributive pharmacists, and pharmacy technicians. There is an exact role of pharmacists during a global disaster. However, it is no standardized pharmacist role during disaster medicine or pandemic and emergency public health. It is a particular method for standardized the Role of pharmacy staff pre-crises and during and after the crises of pandemic finished. Thus, all three phases of situations are not well established at any healthcare institution in the market.

\section{Planning phase}

\section{Scope of the project}

The project covers the Role of pharmacists in pandemic and emergency public health with an emphasis on COVID-19. It is not included in all other disaster medicine. That is including the
Role of the Pharmacist in hospital pharmacy, community pharmacies, and other ambulatory care services.

\section{Vision, Missions, Goals}

The project's vision is to reach Pharmacists' best role in pandemic and emergency public health, emphasizing COVID-19. The message to implement pharmacist contribution in pandemic and emergency public health focuses on COVID-19. The project's goals to declare pharmacists' role during the pandemic and emergency public health (COVID-19). To display the pharmacist's role in hospital pharmacy during the pandemic situation, explore the pharmacist contrition in community pharmacies during the pandemic time. To implement the pharmacist role in pandemic and emergency public health with an emphasis on COVID-19 and avoid unnecessary and additional cost resulting from pharmacists contributing to the pandemic and emergency public health with a focus on COVID-19 on the pharmacy and healthcare system.

\section{Description of the project}

The following policies and actions were put in place for every pharmacy staff and other health care individuals: $\checkmark$ The Role of Pharmacist in pandemic and emergency public health with an emphasis on COVID-19 committee formulated at healthcare organizations

$\checkmark$ The Role of Pharmacist in pandemic and emergency public health with a focus on a COVID-19 committee should consist of Intravenous pharmacist, clinical compounding pharmacist, critical care clinical pharmacist, emergency clinical pharmacists, and pharmacy technician, pediatrics and neonatal nursing representative, neonatal and pediatrics surgical or medical representative, and adults surgical or physician and nurse representative

$\checkmark$ The committee revises pharmacists' role in pandemic and emergency public health, emphasizing COVID-19 standardized and updated at least annually.

$\checkmark$ The education and training sessions of the Role of Pharmacist in pandemic and emergency public health with an emphasis on COVID-19 The committee should be conducted to all healthcare providers, including physicians and nurses, with pharmacy staff.

$\checkmark$ The Role of Pharmacist in pandemic and emergency public health with an emphasis on COVID-19 concepts and regulations distributed to concerned healthcare sectors at the organization

$\checkmark$ The Pharmacist should follow national guidelines and local regulations during the 
pandemic and emergency public health with an emphasis on COVID-19

$\checkmark$ The Pharmacist should educate the public about Heath pandemic and emergency public health, emphasizing covid-19 through answering inquiries or referring them to hotline call 937 at the Ministry of Health.

$\checkmark$ The hospital or community pharmacy staff should provide a continued supply of all medications and including types of sanitizer and disinfectant

$\checkmark$ The hospital or community pharmacy staff In case of not enough supply should compound all medications and including types of sanitizer and disinfectant in the pharmacy if applicable

$\checkmark$ The Pharmacist should prepare and dispense all medications that have required for patients through national infection control with emphasis on the pharmacy infection control regulations

$\checkmark$ The hospital or community pharmacy staff should dispense all medications and including sanitizer and disinfectant with educational materials

$\checkmark$ The hospital or community pharmacy staff should not raise the cost of the medications or over Heath insurance coverage

$\checkmark$ The hospital or community pharmacist and pharmacy technician staff should implement pharmacy infection control all the time with an emphasis on pandemic and outbreak disaster medicine

$\checkmark$ The hospital or community pharmacy collaborates with healthcare professionals to fix the updated management of pandemic virus, emphasizing covid-19 and regular updating accordingly.

$\checkmark$ The hospital or community pharmacy staff collaborate with pharmacy and medical national research centers and contribute with research and publications during the pandemic outbreak covid-19 to produce the best management and medications therapeutic product and vaccines

$\checkmark$ The hospital or community pharmacy staff should assure the patients about the pandemic situation and do not distribute any medications or material or information not efficiently or safe for the patients

$\checkmark$ The hospital or community pharmacy staff should take the guidelines and regulations from trusted resources, including national guidelines from the Saudi center for disease control (SCDC)and international organizations, including the world health organization (WHO) and center diseases control (CDC)

$\checkmark$ The hospital or community pharmacy staff should participate in active surveillance with national infection control about the infected cases and pharmacy infection control surveillance in the pharmacy units and resistance medications or not effective sanitizer or disinfectant $\checkmark$ The hospital or community pharmacy staff should use home delivery or mail medications system during pandemic and emergency public healthcare with an emphasis on covid-19

$\checkmark$ The hospital or community pharmacy staff should use pharmacy automation system and equipment in the preparation and dispensing medications to the patients during pandemic covid-19

$\checkmark$ The pharmacy section should measure the clinical outcome of pharmacists' role in pandemic and emergency public health, emphasizing covid-19.

$\checkmark$ The pharmacy section should measure the economic outcome of the Role of pharmacists in pandemic and emergency public health, emphasizing covid-19.

$\checkmark$ The pharmacy department should document any non-adherence to the standardized Role of Pharmacist in pandemic and emergency public health with an emphasis on covid-19

$\checkmark$ The pharmacy department should fix the pharmacy disaster strategic plan and regulations or pandemic and emergency public health in the future.

\section{Plan of cost management}

Each new project had a management team. It must set out the financial budget, including the cost of pharmacist's performances during a pandemic and emergency public health, emphasizing covid-19, and the educational courses of pharmacy staff, including a clinical pharmacist, distributive Pharmacist, and pharmacy technician, besides the cost of the management team activities, and the cost of updated references. The budget should be supervision over a while until the project is finished and switch to the operating system.

\section{Executing phase Management team}

Project management professionals had various steps. One of the essentialsteps was the executing phase had a team. It leads the program or the project from the beginning until becoming one of the healthcare institutions' operating systems. The group consisted of several members, adults, infectious diseases clinical pharmacists, clinical pharmacists, public health physicians and nurses, pharmacists, pharmacy technician experts in pandemic and emergency public health, pharmacy quality management, and medication safety officer. The team should implement and follow up on the new services with regular updating of medications list with their concentration. The team should also educate and train the pharmacy and pediatrics, and neonates staff about the new services and measure the project's clinical and economic outcome.

\section{Education and training}

Each new project requires special education and training for concerned people. This project needs pharmacists in pandemic and emergency public health, emphasizing covid-19 education and pharmacy staff training, including clinical pharmacists, pharmacists, and pharmacy technicians. The healthcare professionals, physicians, and nurses need another specialized pharmacist in pandemic and emergency public health, emphasizing covid-19 education and training. Furthermore, the team management needs orientation education about the project for all healthcare professionals. The orientation emphasis any new staff healthcare providers joined the healthcare institutions.

\section{Project total quality management}

There are several tools used for total quantity management with new project pharmacists in pandemic and emergency public health, emphasizing covid-19 during the implementation phase and reflecting the impact. The balance scored cards were among them. ${ }^{[45]}$ The tools monitor consisted of four parts: the customer, finance, internal process, education, and innovation. The assessment of healthcare services of the Role of the Pharmacist in pandemic and emergency public health, emphasizing covid-19, was an example of an internal process type. The Pharmacist's clinical outcome in pandemic and emergency public health with a focus on covid-19. It might reflect the education and competency of clinical pharmacists, distributive pharmacists, and pharmacy technicians as examples of the education type. The financial type had a measuring the Pharmacist's cost avoidance in pandemic and emergency public health, emphasizing covid-19. The fourth type was the customer types measuring the patient's satisfaction with healthcare providers, including pharmacists and pharmacy technicians of the Pharmacist in pandemic and emergency public health, emphasizing covid19 in Saudi Arabia.

\section{Risk Management}

There are multiple considered risks, including schedule risks, scope risks, budget risks, personal risks, technical risks, and quality risks. The project is mostly exposed to personnel, budget, technical, and quality risks. [46,47] The project adequately suffered from personal troubles with not trained healthcare professionals or sufficient pharmacists and 
pharmacy technicians on pharmacists in pandemic and emergency public health, emphasizing covid-19. The budget risk not covered the Pharmacist in pandemic and emergency public health, focusing on covid19 education and training courses for all pharmacy staff and healthcare professionals. Another technical risk may be exposed to the technical, limited to electronically updated recourses in pharmacy practice. The project may be exposed to quality risks with not implemented pharmacists in pandemic and emergency public health, emphasizing covid19 safety tools or non-trained personnel. Another risk might be exposed to the scope of the Pharmacist in pandemic and emergency public health with a focus on covid-19; which more performance included

\section{Closing of the project}

During the pandemic and emergency public health, the Pharmacist emphasized covid-19 at all healthcare organizations of governmental and private sectors is required. The demand to improve clinical outcomes of patients during a pandemic and emergency public health, to prevent drug-related errors that lead to morbidity and mortality, and avoid an economic burden on pharmacy and healthcare system including the hospitals and primary healthcare centers services during a pandemic or emergency public health in Saudi Arabia. The project should include pharmacist contribution in pandemic and emergency public health, emphasizing covid-19 each pharmacy unit and keeping supervision through related committees. The pharmacist's role in pandemic and emergency public health, focusing on covid-1 education and training, should be implemented accordingly. The Role of the Pharmacist in pandemic and emergency public health with an emphasis on covid-19 should Update regularly, and expand the pharmacist contribution is recommended in the future. The annual celebration of all pharmacists contributed pandemic and emergency public health with an emphasis on covid-19 pharmacy staff, including Pharmacist and pharmacy technician, is highly recommended in Saudi Arabia.

\section{ACKNOWLEDGEMENT}

None.

\section{CONFLICT OF INTEREST}

The authors declare that there is no conflict of interest.

\section{Funding}

None
Consent for Publications

Non applicable.

\section{Ethical Approval}

This research is exempted from research and ethical committee or an institutional review board (IRB) approval.

https://www.hhs.gov/ohrp/regulations-andpolicy/decision-charts-2018/index.html

\section{ABBREVIATIONS}

MOH: Ministry of Health; KSA: Kingdom of Saudi Arabia; SWOT: Strengths, Weaknesses, Opportunities, and Threats; IV: Intravenous; BSC: Balance Scored Cards; Covid-19: Coronavirus; SCDC: Saudi center of disease control; WHO: World Health Organization; CDC: Center Diseases Control.

\section{ORCID ID}

Yousef Ahmed Alomi org/0000-0003-1381-628X

https://orcid.

\section{REFERENCES-}

1. Alomi YA, Alghamdi SJ, Alattyh RA. History and Strategies of Drug Information Services at Ministry of Health in Saudi Arabia. Pharmacol Toxicol Biomed Reports. 2019;5(1):1-3.

2. Alomi YA. National Pharmacy Practice Programs at Ministry of Health in Saudi Arabia. J Pharm Pharm Scien. 2015;1(2):17-8.

3. Asiri YA. Emerging Frontiers of pharmacy education in Saudi Arabia: The metamorphosis in the last fifty years. Saudi Pharm J. 2011;19(1):1- 8.

4. Alomi YA, Alghamdi SJ, Alattyh RA. Strategic Plan of General Administration of Pharmaceutical Care at Ministry of Health in Saudi Arabia 2012 - 2022. J Pharm Pharm Scien. 2015;1(13):1-8.

5. Alomi YA, Alghamdi SJ, Alattyh RA, Elshenawy RA. The Evaluation of Pharmacy Strategic Plan in Past 2013-2016 and Forecasting of New Vision 2030 at Ministry of Health in Saudi Arabia. J Pharm Pract Community Med. 2018;4(2):93-101

6. Alomi YA, Jamaan AS, Abdullah AR, Shorog E, Alshahran A, Alasmary $\mathrm{S}$, et al. National Survey of Pharmacy Practice at $\mathrm{MOH}$ Hospitals in Saudi Arabia 2016-2017: Preparation of Medications and Dispensing. J Pharm Pract Community Med. 2018;4(1s):s54-9.

7. Alomi YA, Alghamdi SJ, Alattyh RA, Shorog E, Alshahran A, Alasmary S, et al. National Survey of Pharmacy Practice At Ministry of Health Hospitals in Saudi Arabia 2016-2017: Prescribing and Medication Management. J Pharm Pr Community Med. 2018;20(5):S54-9.

8. Alomi YA, Shorog E, Alshahrani A, Alasmary S, Alenazi $H$, Almutairi A, et al. National Survey of Pharmacy Practice at $\mathrm{MOH}$ Hospitals in Saudi Arabia 2016-2017: Drug Monitoring and Patients Education. J Pharm Pract Community Med. 2018;4(1s):s17-22

9. Alomi1 YA, Fallatah AO, Al-Shubaar N, Qohal AA, Alameer LY. The Clinical Outcomes of Pharmacist Interventions in Total Parenteral Nutrition services in Riyadh City, Saudi Arabia. Int J Pharm Heal Sci. 2019;2(2):135-40

10. Alomi YA, Al-Jarallah SM, Bahadig FA. Costefficiency of Clinical Pharmacy Services at Ministry of Health Hospital, Riyadh City, Saudi Arabia. Pharmacol Toxicol Biomed Reports. 2019;5(3s):S20-2.
11. Alomi YA, El-Bahnasawi M, Kamran M, Shaweesh T, Alhaj S, Radwan RA. The Clinical Outcomes of Pharmacist Interventions at Critical Care Services of Private Hospital in Riyadh City, Saudi Arabia. Pharmacol Toxicol Biomed Reports. 2019;5(1):169.

12. Alomi YA, El-Bahnasawi M, Elemam A, Shaweesh T, Antonio EJ. The Economic Outcomes of Pharmacist Interventions at Critical Care Services of Private Hospital in Riyadh City, Saudi Arabia. Pharmacol Toxicol Biomed Reports. 2019;5(3s):S23-34.

13. Alomi YA, Aldosori N, Alhadab M, Alotaibi NR, AlShubbar N, Al-Enazi ADM, et al. The Outcomes of Clinical Pharmacist Consultation Visits at Ministry of Health Hospitals in Saudi Arabia: Medication Safety and Pharmacy Research. J Pharm Pract Community Med. 2017;3(3).

14. Alomi YA, Aldosori N, Alhadab M, Alotaibi NR, Al-Shubbar N, Jadkarim MM, et al. Impact of Clinical Pharmacist Consultation Visits at Ministry of Health Hospitals in Saudi Arabia: Clinical Pharmacy Services and Pharmacy Workforce. J Pharm Pract Community Med. 2017;3(3).

15. Alomi YA, Aldosori N, Alhadab M, Alotaibi NR, AlShubbar N, Alotaibi T, et al. The Value of Clinical Pharmacist Consultation Visits at Ministry of Health Hospitals in Saudi Arabia: Intravenous Admixture Services and Pharmacy Total Quality Management. J Pharm Pract Community Med. 2017;3(3):164-7.

16. Alomi YA, Alanazi AA, Almaznai MM, Albusalih FA. Cost-effectiveness Analysis of Medication Safety Program at Pediatrics, Obstetrics and Gynecology Hospital, East Province, Saudi Arabia. Pharmacol Toxicol Biomed Reports. 2019;5(3s):S12-6.

17. Alomi1 YA, Almudaiheem HY. Cost Efficiency of National Drug Information Center Services through Ministry of Health Hotline Calling Center (937) in Saudi Arabia. Int J Pharm Heal Sci. 2019;2(1):17-20.

18. AlomiYA. National Mass Gathering Pharmaceutical Care Program at $\mathrm{MOH}$ in Saudi Arabia. J Pharm Pract Community Med. 2016;2(3).

19. American Society of Health-System Pharmacists. ASHP statement on the Role of health-system pharmacists in emergency preparedness. Am J Heal Pharm. 2003;60(19):1993-5.

20. Bell C, Daniel S. Pharmacy leader's Role in hospital emergency preparedness planning. Hosp Pharm. 2014;49(4):398-404

21. Bhavsar TR, Kim HJ, Yu Y. Roles and contributions of pharmacists in regulatory affairs at the Centers for Disease Control and Prevention for public health emergency preparedness and response. $J$ Am Pharm Assoc. 2010;50(2):165-8.

22. American Pharmacists Association, American Society of Health-System Pharmacists, Foundation NA of CDS. A Pharmacist's Guide to Pandemic Preparedness. 2007. Available from: www.ashp.

23. Ford SM, Grabenstein JD. Pandemics, avian influenza A (H5N1), and a strategy for pharmacists. Pharmacotherapy. 2006;26(3):312-22.

24. Association CP. Pandemic Influenza A Pharmacist S Guide To Pandemic Preparedness Updated. 2009. Available from: www.pharmacists.ca/ pandemic

25. International Pharmaceutical Federation. The Role of the Pharmacist in Crisis Management: Including Manmade and Natural Disasters and Pandemics. 2005. Available from: www.stanford. edu/group/virus/uda/

26. FIP Health Advisory Coronavirus Sars-Cov-2 Outbreak: Information and interim guidelines for pharmacists and the pharmacy workforce International pharmaceutical federation. 2020.

27. NHS. Novel coronavirus (COVID-19) standard operating procedure Community pharmacy. 2020. Available from: https://www.england.nhs uk/statistics/wp-content/uploads/sites/2/2019/12/ 
NHS-111-MDS-November-2019-Statistical-Note. pdf

28. Saudi Society of Clinical Pharmacy. Executive Summary Recommendations from The Saudi Society of Clinical Pharmacy (SSCP) for Pharmacists During Epidemics and Pandemics. 2020.

29. Liu S, Luo P, Tang M, Hu Q, Polidoro JP, Sun $\mathrm{S}$, et al. Providing pharmacy services during the coronavirus pandemic. Int J Clin Pharm. 2020;42(2):299-304

30. Zheng S, Yang L, Zhou P, Li H, Liu F, Zhao R. Recommendations and guidance for providing pharmaceutical care services during COVID-19 pandemic: A China perspective. Res Soc Adm Pharm. 2020.

31. Ung COL. Community pharmacist in public health emergencies: Quick to action against the coronavirus 2019-nCoV outbreak. Res Soc Adm Pharm. 2020;16(4):583-6.

32. Pharmacy Organization. Pharmacists as FrontLine Responders for COVID-19 Patient Care. 2020.

33. Schumacher L, Bonnabry P,Widmer N. Emergency and Disaster Preparedness of European Hospital Pharmacists: A Survey. Disaster Med Public Health Prep. 2019;1-9.

34. Watson KE, Tippett V, Singleton JA, Nissen LM. Disaster health management: Do pharmacists fit in the team?. Prehosp Disaster Med. 2019;34(1):46-55.

35. Klepser ME. Seasonal and pandemic influenza: Preparing pharmacists for the frontline. J Am Pharm Assoc. 2008;48(2):312-4.

36. Alkhalili M, Ma J, Grenier S. Defining roles for pharmacy personnel in disaster response and emergency preparedness. Disaster Med Public Health Prep. 2017;11(4):496-504.

37. Rubin SE, Schulman RM, Roszak AR, Herrmann $J$, Patel A, Koonin LM. Leveraging partnerships among community pharmacists, pharmacies, and health departments to improve pandemic influenza response. Biosecurity and Bioterrorism. 2014;12(2):76-84

38. Miller S, Patel N, Vadala T, Abrons J, Cerulli J. Defining the pharmacist role in the pandemic outbreak of novel H1N1 influenza. J Am Pharm Assoc. 2012;52(6):763-7.

39. Ford $H$, Dallas $C E$, Harris C. Examining roles pharmacists assume in disasters: A content analytic approach. Disaster Med Public Health Prep. 2013;7(6):563-72.

40. Schwerzmann J, Graitcer SB, Jester B, Krahl $D$, Jernigan $D$, Bridges $C B$, et al. Evaluating the Impact of Pharmacies on Pandemic Influenza Vaccine Administration. Disaster Med Public Health Prep. 2017;11(5):587-93

41. McDonough R. Writing a Business Plan for a New Pharmacy Service. The Dynamics of Pharmaceutical Care: Enriching Patients' Health. 2010;23:1-2.

42. Harris IM, Baker E, Berry TM, Halloran MA, Lindauer K, Ragucci KR, et al. Developing a Business-Practice Model for Pharmacy Services in Ambulatory Settings. Pharmacotherapy. 2008;28(2):7e-34e.

43. Sachdev G. Sustainable business models: Systematic approach toward successful ambulatory care pharmacy practice. Am J Heal Pharm. 2014;71(16):1366-74.

44. PMBOK Guide. A Guide to the Project Management Body of Knowledge. Sixth Edit. Project Management Institute, Inc. 2017.

45. Kaplan RS, Norton DP. The balanced scorecard: Measures That drive performance. Harvard Business Review. 2005;83(7):172. [cited 2020 Mar 15]. Available from: https://hbr.org/1992/01/ the-balanced-scorecard-measures-that-driveperformance-2

46. Ray S. The Risk Management Process in Project Management - ProjectManager.com. Project Manager. 2017. [cited 2020 Mar 15]. Available from: https://www.projectmanager.com/blog/riskmanagement-process-steps

47. Kaplan RS, Mikes A. Managing Risks: A New Framework. Harvard Business Review. 2012 [cited 2020 Mar 15]. Available from: https://hbr. org/2012/06/managing-risks-a-new-framework 